\title{
Protection of Computer Database and Fact Based Works
}

\author{
Neemi Kachhap \\ Student, National University of Study and Research in Law, Ranchi
}

\begin{abstract}
Need for protecting database and fact based works is a major issue for both under Indian and International laws. Multiparty treaty which incorporates both the US and European models are needed for regulating the legislative framework regarding protection of database and fact based works. Database, particularly computer databases touch every one's life either directly or indirectly. Many people use computer databases at work and obtain benefits from it. All those benefits are the product of labour, skill and creativity as well as monetary investment by the database producer. Without adequate protection of databases, the producers will not have enough incentive to produce them. Lack of adequate protection would encourage free riding activities. The database producers waste their efforts because end users as well as competitors in the industry can quickly copy the final product. Thus, the objective of this paper is to analyse the difference between categories of database and to what extent it is protected under the copyright legal regime. This Article lays down the importance of the need of comprehensive legislation for the protection of database and fact based works.
\end{abstract}

Keywords: Databases, Compliations, Copyright, Infringement, Arrangements

\section{Introduction}

The term 'database' generally refers to an aggregate of information systematically arranged and stored in a computer system or in any other form. In the Indian Copyright Act, there are no specific meanings attached to the expression databases or computer databases. Compliations including databases are defined as literary works. The only mechanism of protection for computer programmes and computer data is under Section 2 (o) of the Copyright Act, 1957, which recognizes as the Computer programmes and computer databases as creative work entitled to copyright protection. A database also plays an important role in the development of information market and its products. A database is a collection of data arranged in a systematic manner to allow for the easy and efficient retrieval of the information. It is usually in an electronic form. A database must be distinguished from a database system which is softwares or computer programmes which administers the database. This is an important distinction to keep in mind. Computer database means a representation of information, knowledge, facts, concepts or instructions in text, image, audio, video that are being prepared or have been prepared in a formalized manner and have been produced by a computer, computer system or computer network. For example, the fields for a database that is about people who work for a specific company might include the name, the employee identification number, the address, telephone number, date employment started, position and salary for each worker. A large number of databases are available online from foreign vendors which are finding an increasing market in the country. Over the past few years, India is gradually building up capability in the database field and initiatives are taken by domestic vendors and institutions to commercialize databases and related services in a number of fields. In order to maintain and access the database you will need a DBMS (database management system). This kind of system manages and protects data so that the database is safe and secure. A database consists of tables that include groups of related data fields that are known as records. Databases are not only limited to the computers; in fact, phone book is also an example of database. All of the names alphabetized and each column has its own category. There is a column for your name, phone number, and possibly a street address. With a relational database, all of the data within the row can be pulled up when you are looking for the specific attribute. Facts based works it is not independently eligible for copyright. The facts which are complied by industrious collection or sweat of the brow does not alter the non copyrightable nature of the facts and collection of facts become eligible for copyright protection only through a showing of creativity in the unique or original selection, coordination or arrangements of facts.

\section{Literature Survey}

According to V.K. Gupta, (1995) - This paper has mainly focused in the Business in databases and its related services involve both financial as well as manpower investments. In development of databases, there are considerable investments in computer equipment, software, technical data/expertise and their operations. However, given the technological means, it is quite possible to copy full or substantial part of the databases at a fraction of the costs involved in development of the same. This leads to a conflict of interests between the developers and authors of the databases, on the one hand and the users of the databases, on the other. Restriction on copying without permission and without making payments to the authors of the database is one of the central questions in the protection of databases. According to the author Ahmad Tabrez, (2011) this paper mainly aims at the database which are data collection that allow selection and arrangements of data by attributes that are set up in the database. With the e-commerce entire business are being built upon databases and generating revenue streams from subscribing or advertising. In order to recovers the initial investments of time, money and skills put into it and to avoid the competition, database manufactures generally protects their compilation efforts. Database developers are usually seeking to protect the data complied with by them to face a challenge. According to Apar Gupta, Ranjit 


\section{International Journal of Science and Research (IJSR) \\ ISSN (Online): 2319-7064 \\ Index Copernicus Value (2013): 6.14 | Impact Factor (2015): 6.391}

Kumar.G (2005) in her paper had analyzed the issue of software piracy in particular; one of the biggest areas of copyright infringement in Computer Databases so as industries in the global market progressively come to rely on electronic compliations of data, calls for new, sui generis forms of legal protection for databases have grown apace. Yet, the issue of data protection is not new, nor is the world without the precedents in determining how the issue of data protection ought to be resolved. According to Yadav Kumar Alok, (1997) this paper mainly aims to show that the work related to computer can be protected under copyright law. This discusses about the meaning, history of databases and fact based work. It has been held that compilation of list of clients/customers developed by a person by devoting time, money, labour and skill amounts to "literary work" wherein the author has a copyright under the Copyright Act. As such if any infringement occurs with respect to data bases, the outsourcing parent entity may have recourse under the Copyright Act. According to Nazura Abdul Manap, (May 2012) International Journal of information and Electronics This paper mainly aims that information serves as a commodity which observably needs legal protection, particularly under copyright law. However, one of the doctrines is that the facts cannot be copyrighted. As the facts are normally public domain, they are not deemed to be original to be entitled to protection under the copyright law. According to the author Swarup, Mridushi,(1984) This paper aims for the needs for protecting database which is a major issue both under international and Indian Laws. Multi- party Treaty which incorporates both the US and European models which are needed for regulating the legislative framework regarding the protection of databases. According to the Thorner. Benjamin,(1997) this paper mainly indicates at the discussion of copyright's efficacy with respect to Phonedisc and other similar products and the Computer Databases which must be consider into two issues: i) the basis of protection, and ii) the scope of the protection. This is because the protection gives works as a whole is discrete from a creator's ability to secure judgments for infringement damages stemming from the theft of part of his work. Copyright protection is allowed for any "original works of authorship fixed in any tangible medium of expression. The effect is broad in that a compilation work, one mostly made up of unprotectable facts put together in an unoriginal way, may be a considered to have a sufficient basis for protection when, taken as a whole, if it contains some parts which do supply the required originality. The protection is shallow though, because infringement may be found, and remedies may be awarded in such a case, where either the entire volume is copied, or where the original components (arrangement or selection) itself is copied; this is referred to as the scope of copyright protection. The Florida Law Firm, (2014) this article has emphasized to bridge the knowledge gap between the disciplines of Law and Information Science and Technology. This article discusses both practical and legal methods of protecting a computer database from unauthorized copying and use. The intentional use of "seeds" and "signatures" in a database, when combined with the three main vehicles of legal protection: copyright, trade secrets and contract; which can create a powerful defense against the "computer pirate." According to
Hayden F. John, (1991) this paper has mainly focused on the increased sophistication of computer databases has made them invaluable tools for a range of uses. At the same time unprecedented advances in computer technology had helped to spur growth in the computer information industry. As computer have become more powerful, they have also become more affordable. As a result, systems previously found only in research labs are now standard fixtures in offices and homes. Increased accessibility has created vast numbers of users demanding additional products and services, and this has been a further push for expansion in the computer information industry as a whole.

\section{Problem Definition}

A database is eligible for copyright protection if it is a result of great deal of effort, skill and labor. For getting such protection it has to satisfy the test of 'originality'. Arrangement of database should in a effective way for users. In the world of digitalization, the problem of the copyright infringement in Computer data bases has become a very big challenge. So, this article aims to address the challenges posed to copyrighted works by communication in Computer databases and fact bases works in order to suggest some viable solution to them. A detailed study will be made of the legislations that have been enacted in the two countries selected for study- USA and India. Their level of inadequacy and the lacunae in them shall be identified. The limited copyright protection provided to databases makes it imperative that database owners and developers protect their databases through contract law. Through an enforceable contract, typically in the form of a license to use the database, the end user can be prohibited from extracting data from the database for uses other than those intended by the database owner. This can be done through a comparison of the enactment of the two countries and their further comparison with an ideal model. The study shall also be extended to the international treaties and agreements that were adopted at the international level and which inspired the enactment in these countries. The lacuna in them shall also be identified and solutions suggested. These can looked upon as the right applies to databases whether or not their arrangement justifies copyright or not and whatever the position may be regarding copyright in individual items in its content. The focus upon contents, rather than organizational structure, is intended to give a right where the contents have been wholly or substantially taken out and rearranged so as to provide quite different organizations to essentially be the same material and re- organizations which would not necessarily amount to the infringement of copyright in the original arrangement. The most important step which should be taken here is to finish an international treaty on database and fact based protection that can be adopted by jurisdictions throughout the world. However, to do so, consensus should be reached on the best way to balance the rights, liabilities and exceptions that would form its protection. Thus, these issues should be debated or resolved particularly between different countries to achieve an appropriate balance between the protecting commercial activities and preserving the public domain. 


\section{Methodology / Approach}

Research Design- The research design which is adopted in this Article is both descriptive and explanatory. It describes a particular problem and then explains the phenomenon in terms of factors responsible and feasible solutions. It also follows a causal research design as it gives the reasons for a particular happening, which forms the base of further study to solve the issue. It is a doctrinal study (not based on empirical data).

Method of Data Collection-The research article is based on secondary data based on articles, books, newspaper items and reports of various committees and organizations.

\section{Results / Discussion}

\subsection{Need to Protect the Property in Database}

Databases are useful collections of materials which consequently have value independently of their several items of content.[1] They are often creative and usually costly to compile, present and maintain. In the information society, they are increasing economic significance. Those who create databases and those who invest in their way of development and maintenance, may reasonably except to enjoy a return on their investments, but once a database has been made publically/available securing a financial return from it is likely to be difficult, if not impractical, unless some form of right is recognized in the database as such.[2] There is always a view that taking a databases and simply rearranging the data, creates something new and is not infringed of the original database copyright. The alternative view is that now-days the data in a database are not placed in the computer memory in any particular order, and are simply available for retrieval so the former view implies an infringement of the original database.[3] Another view states that if there was no skill in selecting the individual items that go in a compilation or database and if there is no skill in the arrangement (no addition of the keywords or indexing terms, simply a listing), then such a compilation should not justify the copyright protection. [4] Database manufacturers base their call for a new right on purely the economic grounds unlike, existing forms of intellectual property law that are the grounded philosophically on the promotion of creativity, or "moral rights". An author tends to maintain the copyright on a creative work even when he or she receives no remuneration for it. Simply, so that the other people won't change it and ship it around in garbled form. But database manufacturers have little reason to be concerned that how people use facts from the collection unless the manufacturers markets are being threatened. The doctrine of unfair competition and misappropriation have long been used to protect database manufacturers, like other providers of goods and services, from losing business to the competitor who become "free riders" by simply republishing the work that the original manufacturer has taken so long to acquire.[5]

\subsection{Protection of Databases under Copyright}

Most national systems have gradually moved in the direction of providing protection to computer software and databases under copyright law. A work is copyrightable if described as being fixed in a tangible medium of expression when its embodiment in a copy or otherwise communicated for a period which is more than transitory duration. In other words, if a work is created on a word processor so that it is projected briefly on screen or captured only momentarily in the memory of a computer that work is not fixed and cannot be protected by the copyright. Computer databases, which are electronic files of information "formed by the collections, assembly, and the arrangement of pre-existing materials or data" are thus, considered protected, provided the resulting work as a whole which constitutes the original authorship. In the theory, databases may be protected per se under copyright within a national law. Key issues in copyright protection of the databases are only concerned with individual records within the database are recognized as literary works and are thus individually and separately have their own proprietary values and also the mode of compilation of the database may be protected solely as compliations because skill and effort were extended in making the collection.

However what is important is that compilation of databases which needs the classification systems to organize data. The intellectual skills of "data organization" facilities quick retrieval and a variety of analyses of data. Databases whether in online form, CD-ROM form, or any other form and thus treated as a standard copyright work. Such compliations should not be downloaded or copied in any other way without prior permission (except for small portions only for fair use such as research or private study). Although protection of databases under copyright is the most sought after arrangement yet there are alternative opinions preferring lesser control in the database area in the interest of creating a strong database industry. Generally, three broad approaches are followed in the protection of databases are as follows:

(i) Firstly, steps have been taken to incorporate database protection in the copyright laws.

(ii) Secondly, in addition to copyright protection, additional restrictions are put on the use of databases through 'Contracts'.

(iii) Thirdly, legislative measures should be enacted for a sui generis system of protection for databases.

The present debate regarding database protection can be viewed simply as an extension of the historical clash between two conflicting models of copyright protection for compliations. The first model says that database and factual compliations receive the protection per se i.e without any showing of creativity of original authorship. Proponents of this theory, better known as sweat of the brow doctrine, justify their position by arguing that the protection should be extended to databases as a reward for the hard work and investment required to compile the facts and information contained in the database.[6] and such a reward provides compliers with the incentive to develop 


\section{International Journal of Science and Research (IJSR) \\ ISSN (Online): 2319-7064}

Index Copernicus Value (2013): 6.14 | Impact Factor (2015): 6.391

new databases. Under this doctrine, protection extends to the otherwise unprotected facts contained in the compliations.[7] The second model of intellectual property rejects the notion that databases without any originality or creativity should be protected.[8] It would only extend copyright protection to the "expression", or arrangement of facts in the database but not the facts themselves.[9]

\subsection{International Framework for Protection of Databases}

Berne Conviction: It is the Protection of Literary and Artistic works, which the guarantees quite minimal protection for compliations of literary and artistic works. Article 2(5) is restricted to collection of literary and artistic works rather than collection of information where the individual piece of information were not in a form entitling copyright protection.

Trips: It is referred to the databases and set up of a framework for their protection. Its formula summaries and resolves the controversies concerning database protection by using the fundamental approach that copyright in a database concerns its structure rather than its content. It is the mode of compliation that is protected and not the material question, which are assembled to create the database in question.

Copyright Treaty: Protection under this treaty is conditional upon the collection being selected or arranged in such a way as to constitute an intellectual creation.[10] There are also more general provision concerning copyright protection that have impact on legal protection of database. These provision are concerned with one of the electronic dissemination of copyright material restrictions on [11], manufacturer, important and distribution and use of devices that may be used to circumvent technological measures of protecting the contracting parties, [12] providing protection for rights of management information to the owners of databases subject to copyright protection.[13]

\subsection{New Technologies: Issues and Trends}

Cyberspace: By cyberspace, one means the sum total of all electronic messaging and information systems including the commercial data services, research data networks and electronic publishing, networks and network nodes, E-mail systems, electronic data interchange systems, and electronic funds transfer systems. In principle, the databases and compliations are protected under the copyright laws even if these enter the cyberspace, the fact that they are easily accessible tend to make such protection rather meaningless. The ease of copying and distribution make such copyright enforcement difficult.

CD-ROM Technology: The CD-ROM format provides reliable access to a wide variety of media, such as computer data, text, audio and video. A CD-ROM is made of plastic and the data stored on each disc are digitally recorded on one track that begins at the centre of the disk and extends about 3 miles to the outer edge of the disc.
The strength of CD-ROM format is its ability to provide access to large amounts of data through powerful search and downloading functions. Digital technology has posed a dilemma for the copyright works including databases. The key issue is, should downloading be permitted.

Multimedia: The most recent trend in CD-ROMs is the growth of multimedia databases. These databases, which incorporate text and images, audio, video or animations (or a combination), represent a fundamental change in the way information is presented. The multimedia titles on CDROM have doubled from 40 in 1989 to 1435 in 1993 . The copyright implications of multimedia are more complex than those for databases. This newly coined term refers to the use of DIP (document image processing) equipment, which is being increasingly used by large organizations to scan in and achieve internal documentation, typically onto write once read many times discs. These discs, or other storage media, can then be accessed from all the multiple locations within the organizations using local and wide area networks to retrieve and inspect the original documents.

Issue of Downloading: Downloading is the electronic transfer of information from one database to another including that from an online database service through one's own local microcomputer. Many publishers accept the idea that there are legitimate reasons for the temporary retention of data obtained from an online search and they are willing to give such permission. Normally, downloading from a database shall amount to copyright infringement. However, in view of more and more users wanting to retain records permanently to make them part of their own local electronic library, a need is felt to give attention to such user needs.

\subsection{Protecting Personal Information in Databases}

These days many databases are established which contain the personal information about individuals e.g. members of a library or the business card holders. Such databases have raised issues regarding protection and misuse of personal information of individuals. Misuse may occur in this. Alternatively, if a database service misspelled the name of an author in reference to one of the author's papers then the evaluated performance of the author measured in terms of the number of articles published may be lowered. Many countries have responded to the privacy concerns of such databases by introducing data protection legislation.[14] The legislation allows individuals who are the subject of such databases the right to know what records there are about them and the contents of those records. Now a days leading libraries like British Council Library obtains a declaration from the members to the effect whether their personal information can be made available to other databases or not. The issue whether data protection applies to data on CD-ROM is not yet settled

\subsection{India's position on a sui generis international treaty}

The issue of database protection has been on the agenda of the WIPO Standing Committee on Copyright. Studies have been commissioned on the economic implications of 


\section{International Journal of Science and Research (IJSR) \\ ISSN (Online): 2319-7064}

Index Copernicus Value (2013): 6.14 | Impact Factor (2015): 6.391

database laws, especially for developing countries. Note that at the third Session of the Standing Committee, a number of countries took the view that the need for additional protection had not yet been demonstrated. These countries included India. It was reported that the Indian delegation argued that copyright protection was sufficient and working well and that there were concerns about the possible effects of database rights on the development of science, technology, research and education.

\subsection{Protection in the Indian Scenario}

\section{Database protection under the Information Technology Act, 2000}

In 1999 prompted by United Nations Commission on International Trade Law's Model Law on Electronic Commerce (MLEC) and notable developments in Asian countries such as Singapore, Malaysia, India commenced with providing a legal framework for internet activity.[15] The Union Cabinet approved the bill on May 13, 2000 and it was finally passed by both the houses of Parliament by 17 May, 2000. The Act received presidential assent on $9^{\text {th }}$ June,2000 as per the Indian Information Technology Act, 2000.[16] India aims to regulate all digital activity through Information Technology Act, 2000. However the database protections provided it to under the act is fairly limited.[17] Section 43 of the Indian Information Technology Act, 2000 which imposes liability to pay damages by the way of compensation not exceeding one crore rupees to the person so affected[18] and if "any person without permission downloads, copies, or extracts any data, computer database or information from such computer system". The section defines "database" as the representation of the information, knowledge, facts, concepts, or instructions prepared in a formalized manner. Though this section can be applied for electronic databases, its effectiveness is still to be tested for granting protection to databases.

\section{Database protection under the Copyright Act, 1957}

Most legal systems have steadily moved in the direction of providing protection to computer software and databases under copyright law. In principle, it is the skill, labour and judgement of the author that is protected irrespective of the form in which the product appears e.g. whether one types a book on an old-fashioned typewriter or transforms it in a digitized form or in handwritten form. Any reproduction of the work including translations is considered a reproduction of the original. Protection for databases is in India has been tested in the traditional intellectual property regime of copyright protection. This is contained under the Indian Copyright Act, 1957, post 1994 amendments. The Indian Copyright Act, 1957 was amended in 1994 to extend more effective protection to owners of copyright by making provision for the special nature of computer programmes as literary works and for the protection of computer generated works.

Database manufacturers are relying on copyright laws as databases are protected as compliations under literary works. In India, a member of the Berne Convention and
TRIPS Agreement, the requirement of originality in selection or arrangement of the contents of the database is required to attract copyright protection.[19] The courts seem to uphold the "sweat of the brow" theory or the skill, labour and judgment test in deciding copyright protection against infringement. In the case of McMillan v. Suresh Chunder Deb,[20] Govindan v. Gopalakrishna,[21] and others, the courts held that a compilation developed through devotion of time, capital, energy and skill, though taken from a common source, amounted to a literary work and was therefore protected under copyright. The courts based their decisions on the point that no person was entitled to appropriate for oneself the fruits of another's skill, labour or judgment and even a small amount of creativity in a compilation was protected. These cases clearly show that the "sweat of the brow" doctrine is being followed by Indian courts in deciding copyright protection to databases. The applicability to database protection was examined in Diljeet Titus, Advocate \$ Ors. v Alfered A. Adebare \$ Ors [22] where the court held that in the case of compliations, another person can make similar compilation, but cannot infringe upon the copyright of the previous compiler by appropriating the fruits of his labour.[23] Rejecting protection for "Head notes" prepared by the plaintiff publishers, the Court observed that protection of copyright must inhere in a creative, original selection of facts and not in the creative means used to discover the facts. The Court was then referred to the US Supreme Court's Feist in the decision [24]and said that there should be a modicum of creativity in the selection, arrangement or co-ordination of the contents of a database to attract copyright protection.

\subsection{Database Licensing and Preemption}

As a result of the Supreme Court's holding in Feist, it is clear that not all databases are protected by copyright law as compliations. In order to be protected, the database must be original in its selection, coordination, and arrangement. The mere alphabetic arrangement of data is not original enough for protection by copyright law unless there is some originality in the selection or coordination of the data. In addition, Feist makes it clear that even if a database is protected by copyright law as an original work, this protection will not prevent an individual from extracting factual data from the database (short of copying the selection and arrangement of the database as a whole). The limited copyright protection provided to databases makes it imperative that database owners and developers protect their databases through contract law. Through this an typically in the form of a license to use the database, the end user can be prohibited from extracting data from the database for uses other than those intended by the database owner. For instance, a contract could prohibit the end user from making data extracted from the database available to third parties, or from including the extracted data in a new database.

\subsection{Databases as Compliations}

Databases are generally protected by copyright law as compliations. A database of facts is also protected as a compilation, assuming the grouping contains enough 


\section{International Journal of Science and Research (IJSR) \\ ISSN (Online): 2319-7064}

Index Copernicus Value (2013): 6.14 | Impact Factor (2015): 6.391

original expression to merit protection the discussion is given in the case of Feist. An example of a protectable grouping of facts would be a database of Internet locations for selected legal articles. Each location consists merely of factual information, namely that a particular article can be found at a particular URL location on the Internet. There is no copyright protection for each location. Therefore, while the individual locations can be copied by others, if an entire database of locations (or a substantial portion of the database) were copied, the copyright in the compilation would be infringed. The creative, original expression that is being protected is the selection of locations for the database.

\subsection{The Current Rule's Implications for Databases}

Protection based on an "original arrangement" shares the same weakness as the prohibition on copying. Any party with the requisite technical expertise can easily avoid liability by simply rearranging the data. The copying party will probably have rearranged the data already as a means of avoiding infringement based on verbatim copying. Though it mainly offers more protection than "original arrangement," "original selection" is also of limited value. Initially, database developer must establish that the chosen selection was sufficiently subjective to merit protection. Even then, a potential infringer is only prevented from copying a "substantial portion" of the developer's selection. Protection based on original selection and arrangement is inadequate for databases. The contribution offered by a database is the informational value of its collection of a comprehensive set of data, and much of the costs of database development result from this collection process. Protection based on selection and arrangement, though, prevents copying of only the format of the data rather than the data itself and thus fails to protect the database's main contribution. In fact, the fair use provision of the copyright statute would only need minor alterations to reflect the policy of allowing liberal use of information by the public while providing extensive protection against competing uses of the information. The system would also need to provide for limited form of the idea-expression distinction. This would prohibit protection of the idea underlying a database or factual compilation. Without this distinction, a compiler could prevent others from creating similar compliations even through reference to the original sources. However, this system of protection is based on a desire to protect a compiler's efforts in gathering information. Protection of the underlying idea goes beyond protection of this effort and thus exceeds the purpose of this system. To protect the ideas these would risk the removing information from public access rather than just preventing subsequent compilers from stealing the fruits of the initial compiler's labors.

\subsection{Protection of Fact Based Works}

The non-protection of facts is one of the cardinal principles of our intellectual property system. Facts are the building blocks of innovation and creativity. By keeping facts in the public domain and widely available, the intellectual property regime makes sure that future generations have access to the raw materials out of which they can fashion tomorrow's works. In the words of "all facts scientific, historical, biographical, and news of the day...are part of the public domain available to every person."'[25] To be clear, an "original selection and arrangement" of facts can be copyrighted, but it is the selection and arrangement, the creative ordering of information, rather than the underlying facts themselves that is safeguarded. Rightly or wrongly, the database industry finds this troubling.[26] Despite evidence that the industry is flourishing,[27] it feels that the current system leaves it vulnerable to copying. Therefore, it has pushed for legislation that would provide an additional measure of protection for the facts the raw information within databases. As a rule, facts cannot be copyrighted. In such cases, copyright protection extends only to the creative aspect of the work, not to the facts contained in the database or compliation. A "fact compilation" is created by selecting data that is in the public domain like name, addresses, and telephone numbers and arranging the data in some minimally creative manner. Almanacs, catalogues, and other databases are also examples of fact compliations. To qualify for copyright protection, compilation of facts must meet three distinct elements:

1. The work must be a collection and assembly of preexisting material, facts, or data;

2. The work must contain the selection, coordination, or arrangement of those materials and;

3. The work is created by virtue of the particular selection, coordination, or arrangement of an original work of authorship.

In fact, the selection methods that others have used may unknowingly be used; novelty is not required. For the originality requirement, the author needs only to make the arrangement or selection independently, without copying the selection or arrangement from another work, and also display some minimal level of creativity. While most factual compliations will pass the test, there will be a small number of works wherein the creative spark is completely lacking or may be minimal that it can be considered as virtually nonexistent. Therefore there will invariably be some fact based works in which the selection and coordination, and arrangement are not always sufficiently original to trigger copyright protection in any way at all. According to the copyright law, the term 'compilation' includes collective works as well. A copyright compilation enjoys only limited protection. The copyright only covers the author's original contribution not the facts or information conveyed.

The 1991 US Supreme Court decision in Feist Publications Inc. v. Rural Telephone Service Co. held that factual matter is not subject to copyright protection because it is not original to the author, thus dramatically rejecting a two-century-old tradition of protecting factual compliations under copyright. The debate over fact-based works has grown still more complicated since Feist with enactment of the initiatives that extend the protection of databases. A number of legal scholars have voiced their opinions on how Congress should react to the Court's decision and the Database Directive, but none have put 


\section{International Journal of Science and Research (IJSR) \\ ISSN (Online): 2319-7064}

Index Copernicus Value (2013): 6.14 | Impact Factor (2015): 6.391

forth a viable solution or questioned the debate's underlying assumptions.

\subsection{Proposed Legislative Measures}

The Indian government has proposed several amendments to the IT Act, which are likely to be implemented soon. The proposed amendments widen the liability for breach of data protection and negligence in handling sensitive personal information. Additionally, the Government of India, with the help of the Department of Information Technology, is currently working on a holistic law on data protection based on the European Union directives. Further, the government plans to create a "Common Criterion Lab," backed by the Information Security Technical Development Council, where the product security can be undertaken.

\section{Conclusion}

From the study conducted, it can be concluded that while the Indian laws have not much advanced enough to incorporate new threats to copyright protection, and failed to do so. With the increased digitalization of data, India is increasingly seen as the back office of the world. The creation and exploitation of the databases is a natural component of such services. Without the granting of an adequate standard of protection to the authors of the databases, the economic boom will not be sustainable. The lack of a comprehensive legislation pertaining to database protection has been a matter of concern. Even though the database protection laws are not specifically laid down in any statue as yet, Indian industry has begun the process of senstising the Government and the masses regarding the importance of these laws. Although weight has been given to database protection under both the International and Indian laws, a few issues still remain unanswered. Further, at the international level there is an immediate need of a party treaty, which incorporates both the US and the European models of database protection, for regulating the legislative framework regarding the protection of computer databases. The need for a law on data protection is the paramount if India sustains investor confidence, especially among foreign entities that send large amounts of data to India for back-office operations. The proposed legislation for data protection will ensure adequate safeguards, and also appoint a regulator to monitor the collected data and its usage.

\section{Future Scope}

The practice of storing and retrieving copyrighted works in computer systems maintenance and operation of database is likely to grow. In view of the development towards the international computerized information systems and the increase of transborder data flow, it is highly desirable to have international cooperation in reaching common and practical solutions to problems of database protection.

\section{References}

[1] David w. Carstens, Legal Protection of Computer Program and Software: Copyright, Patent, and Trade Secrets, 20 J. Contemporary. L. 13 (1994)

[2] J.H. Reichman \$ Pamela Samuelson, Intellectual Property Rights, 50 Vand. L. Rev.51 (1997)

[3] Bruce Yandle \$ Andrew P. Morris, The Technologies of Property Rights, 28 Ecology L.Q 123,(2001)

[4] Ginsburg, Jane C, Creation and Commercial Value: Copyright Protection of Works of Information 90 No. 6 Columbia, (1990)

[5] Askanzia , Jennifer, The Future of Database Protection in Indian Copyright Laws (2001)

[6] Russell G. Nelson, Seeking Refuge from a Technology Strom:The Current Status of the Database Protection Legislation 6 Journal Intellectual Property Law 453 (1999)

[7] Stephen Maurer, Raw Knowledge: Protecting Technical Databases for Science and Industry: Februrary, 2011

[8] Hasan, A Deveci, Databases: Is sui Generis a stronger bet than Copyright, 12 International Journal of Law \$ Information Technology 178 (2004)

[9] Michael J.Bastian, Protection of the Databases works: Harmonization of United States, Foreign and International Law 22 international\$ Comparative Law Review 429(1999)

[10] Article 4, Copyright (WTC), WIPO Copyright Treaty (1996)

[11] Article 8, Copyright Treaty

[12] Article 12, Copyright Treaty

[13] Article 3, Database Directive; Section 3. A(1), CDPA, 1988

[14] Sathyanarayana, NV: Copyright for Database, November, 1995

[15] Indian Carr, India joins the Cyber - Race: Information Technology Act, 20006 (4) International Trade Law and Regulation 122 (2000)

[16] Information and Technology Act,2000

[17] Andrew Lawler, Database Access Fight Heats Up, 27 SCIENCE 1047 (1996)

[18] Section 43, Information Technology Act, 2000

[19] Article 10(2), Agreement on Trade related Aspects of Intellectual Property Rights, April,15, 1994

[20] I.L.R. 17 (Cal) 951, 961

[21]AIR 1955 Mad 42

[22] 2006 (32) PTC 609 (Del)

[23] Eastern Book Company v. Desai, AIR 2001 Delhi 185

[24] Feist Publication, Inc. v. Rural Telephone Service Co. 499 U.S. 340(1991)

[25] Idd. Feist was the copyrightability of information in telephone directories.

[26] Laura D'Andrea Tyson and Edward F. Sherry, Statutory Protection for Databases: Economic \& Public Policy Issues (unpublished report for the Information Industry Association, 1997), September 1, 2004).

[27] Jason Gelman; Legal Publishing and Database Copyright Protection and accompanying article by Kerri Smith, Protecting Proprietary Information: The Power Of Agreement. 


\section{International Journal of Science and Research (IJSR) \\ ISSN (Online): 2319-7064}

Index Copernicus Value (2013): 6.14 | Impact Factor (2015): 6.391

[28] Chalton. S, "The effect of the E.C Database Directive on United Kingdom Copyright Law in Relation to Database: A Comparison of features" (1997) 6 EIPR 248

\section{Authors Profile}

Neemi Kachhap is a student pursuing $3^{\text {rd }}$ year of BA LLB (Hons) from National University of Study and Research in Law, Ranchi.

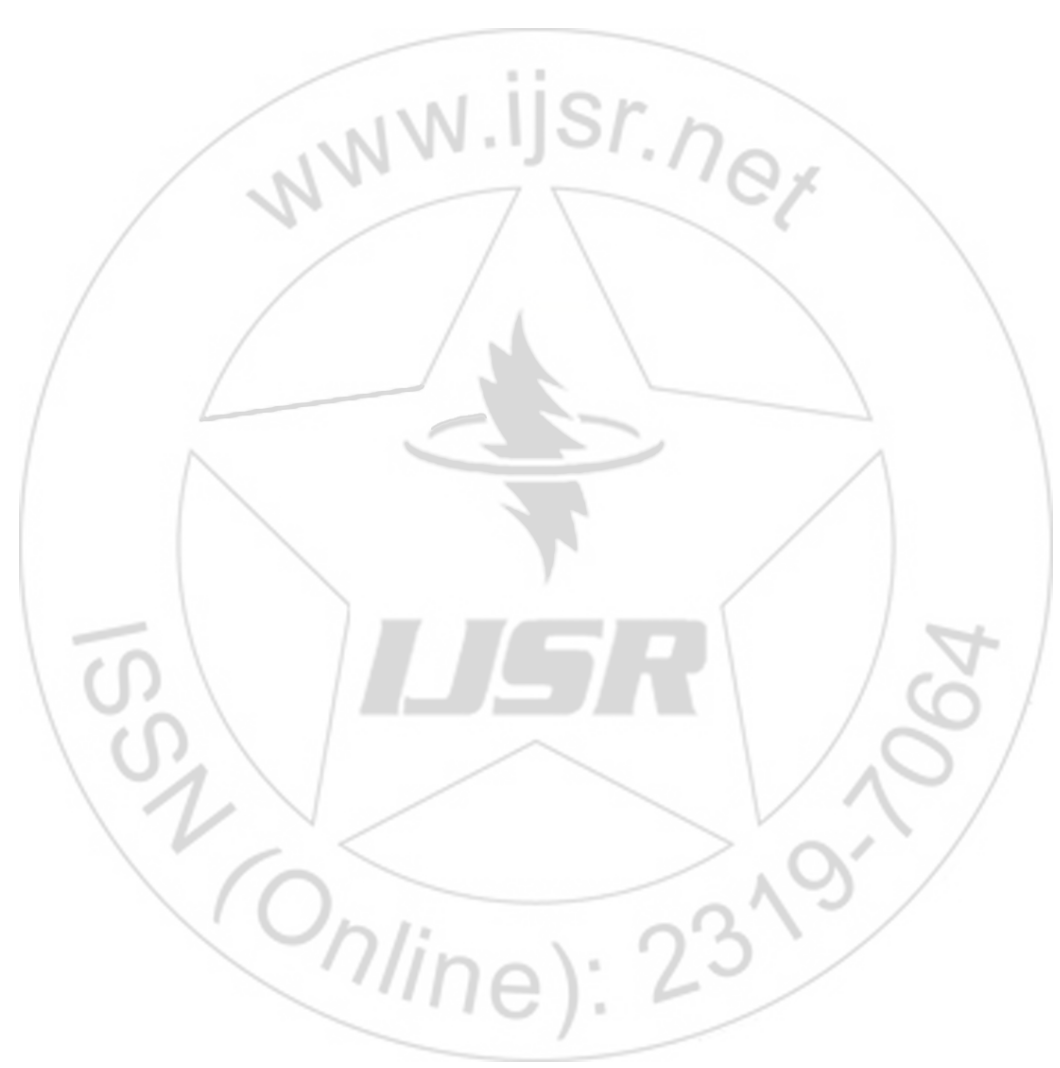

Volume 5 Issue 5, May 2016 